\title{
Maternal Understanding Regarding Women Nutrition during Breastfeeding
}

\author{
Gabriela Olagnero1, Luciana Barretto², Adriana Wiedemann², Raúl Terraza², Mabel Susana Poy², \\ Laura López ${ }^{2}$
}

${ }^{1}$ Scientific Coordination for Latin America, Danone Nutricia Early Life Nutrition, Buenos Aires, Argentina

${ }^{2}$ School of Nutrition, University of Buenos Aires, Buenos Aires, Argentina

Email: golagnero@gmail.com, lucianabarretto@hotmail.com, adrianazwiedemann@gmail.com, raulterraza@yahoo.com.ar, mpnutri@yahoo.com.ar, lblopez@fmed.uba.ar

How to cite this paper: Olagnero, G., Barretto, L., Wiedemann, A., Terraza, R., Poy, M.S. and López, L. (2018) Maternal Understanding Regarding Women Nutrition during Breastfeeding Health, 10, 1661-1672.

https://doi.org/10.4236/health.2018.1012125

Received: August 29, 2018

Accepted: November 30, 2018

Published: December 3, 2018

Copyright $\odot 2018$ by authors and Scientific Research Publishing Inc. This work is licensed under the Creative Commons Attribution International License (CC BY 4.0).

http://creativecommons.org/licenses/by/4.0/

\begin{abstract}
Introduction: Breastfeeding mothers' nutritional status affects milk quality and children's nutrition in a key period for life. Objectives: Identifying and describing breastfeeding mothers' social representations during this period related with nutrition as self-care; connotations referred to food products and supplements; post-partum weight retention and information sources consulted on this matter. Materials and Methods: Ten in depth interviews were performed in healthy adult breastfeeding mothers. Interviews were analyzed with a qualitative methodology considering Health Beliefs, PRECEDE and Health Promotion models, employing the Grounded Theory. Results: Women consider nutrition as a health conditioning factor and refer dietary changes implementation during pregnancy, which are not always kept during breastfeeding. Disorganization was mentioned regarding feeding and commensality, prioritizing their child's health over their own. Vegetables and liquids are attributed to positive connotations, referring increased consumption. Certain foods are limited as they are considered less healthy ("junk food", sweets, sodas, cookies, spices, coffee and mate) while others, like milk, have been associated with negative effects. Insufficient weight gain during pregnancy is valorized as an achievement due to pairs approval and appearance. Association between breastfeeding and previous weight recovery is weak and doubted. Lack of information on feeding and breastfeeding even among health professionals is recognized. In case of doubts, mothers follow the closest belief affectively. Conclusions: Identifying and characterizing beliefs and barriers for maternal eating practices allow including socio-cultural aspects both in the design of public health policies and in individual nutritional counseling.
\end{abstract}




\section{Keywords}

Breastfeeding, Maternal Feeding, Perceptions, Barriers, Information

\section{Introduction}

Nutrition during early stages of life affects growth and represents a risk factor for future chronic diseases. These stages include the so-called "first 1000 days" or window of opportunity for nutritional interventions ranging from conception to the first 2 years of life [1].

During breastfeeding, especially if it is exclusive, mother and son interlace their present and future health. The components of human breast milk provide the nursing baby with signs about the environment from an immunological and nutritional point of view. Milk production and composition are affected by three aspects of the mother's nutrition: regular eating, nutrient and energy reserves and the use of nutrients influenced by hormonal environment. Breastfeeding increases women's nutritional needs, since their own nutrition affects milk quality and the feeding of the nursing baby, impacting on their own nutritional status and the future pregnancies they may have [2] [3].

Health policies in Argentina aimed at promoting breastfeeding for its short and long-term benefits lead to satisfactory results, since $95 \%$ of women are breastfeeding when discharged from hospital and 53\% are able to keep exclusively breastfeeding up to the 6th month [4] [5]. However, there is no information published to characterize the mother's diet and/or nutritional status during breastfeeding [6].

\section{Objectives}

Identifying and describing breastfeeding mothers' social representations during this period related with the following areas:

- Importance given to self-care in relation to the diet, identifying the determining factors for healthy habits and coping strategies.

- Connotations referred to food products, drinks and supplements.

- Body image and post-partum weight retention.

- Commonly consulted information sources.

\section{Materials and Methods}

In-depth interviews were carried out having the following inclusion criteria: healthy women, over 18 years old within the first 6 months post-partum on exclusive breastfeeding or, if infant formulas are included, less than two bottles a day are given. Women on a special diet for a pre-existing condition (e.g. diabetes, celiac disease, high blood pressure, dyslipidemia, metabolic syndrome) or having a disease or medical condition which, based on the Investigator's judgment, could impact on the interview, were excluded. Sampling was intentionally 
carried out through a voluntary invitation and an announcement posted on FUNDALAM's (Fundación de Lactancia y Maternidad [Breastfeeding and Motherhood Foundation]) website from April to June 2015. Women were contacted for enrolment by e-mail. Data collection had been carried out in June 2015 and ended when the knowledge saturation criterion was fulfilled, i.e., when the inclusion of new interviews did not bring about an automatically new understanding. The Protocol had been approved by an Independent Ethics Committee. All participants signed the Informed Consent before the interview.

Semi-structured interviews included the following topics:

- Self-care: Exploration of health concept, self-care strategies for one's own and baby's health, perceived barriers and benefits.

- Diet: Exploration of habits and changes in diet and their link with breastfeeding (Food, drinks, supplements).

- Weight: Exploration of representations, beliefs, values in relation to weight increase/body image during pregnancy and its relationship with breastfeeding.

- Information sources: Exploration of sources of information about mother's care during breastfeeding, references, family influence and health care professional's role.

The guide explored the main constitutional categories of the Health Beliefs Model (Becker and Maiman Version, 1975), PRECEDE Model (Green, Kreuter, Deeds, 1991) and Health Promotion Model (Pender N, 2011) [7] [8] [9].

The Investigator introduced himself as a member of the health team and conducted the interview at the women's home or work address. Interviews were anonymized, recorded in digital audio and transcribed into text using F4 Software.

Data analysis was carried out through qualitative techniques using Atlas ti 7.O. Software, following the coding grounds of the Grounded Theory from Anselm Strauss (open and selective coding) aimed at identifying emerging conceptual models [10] [11]. Table 1 shows the topics explored.

\section{Results}

Ten mothers living in the City of Buenos Aires were interviewed (Table 2). Among them, 4 were primiparous and 9 referred they were feeding their baby through exclusive breastfeeding. Mean age was 32.7 years old. In total, $90 \%$ of them achieved a higher education level (tertiary and university) and $60 \%$ were in their maternity leave.

\subsection{Self-Care and Value of a Healthy Diet}

Most mothers believe that a "healthy" diet is beneficial for breastfeeding, especially for the baby. They referred they had made dietary and health care changes since they got pregnant based on recommendations from health professionals (obstetricians), on their own (based on considering an aim: baby's health and 
Table 1. Analysis categories according to each adherence model and categories emerging from grounded theory.

\begin{tabular}{|c|c|c|c|}
\hline Health Beliefs & Health Promotion & Precede & Grounded Theory \\
\hline Value of the Target & $\begin{array}{l}\text { Perceived Personal } \\
\text { Self-Effectiveness }\end{array}$ & Beliefs (Knowledge) & \\
\hline Estimation of the & & & Open and Selective \\
\hline $\begin{array}{c}\text { Ability to achieve the } \\
\text { Target }\end{array}$ & Perceived Health Status & Attitudes \& Values & $\begin{array}{c}\text { Coding. } \\
\text { Code Examples: }\end{array}$ \\
\hline Perceived Benefits & $\begin{array}{c}\text { Health Definition, } \\
\text { Importance and Perceived } \\
\text { Control }\end{array}$ & Personal Consequences & $\begin{array}{c}\text { Value of a Healthy Diet } \\
\text { Food Products and } \\
\text { Drinks } \\
\text { Supplements }\end{array}$ \\
\hline Perceived Barriers & $\begin{array}{l}\text { Perceived Benefits and } \\
\text { Barriers of Health } \\
\text { Promoting Behaviors }\end{array}$ & Skills & $\begin{array}{l}\text { Food Products affecting } \\
\text { the Milk or the Baby } \\
\text { Connotations referred to }\end{array}$ \\
\hline Perceived Susceptibility & Biological Features & $\begin{array}{l}\text { Environmental } \\
\text { Response }\end{array}$ & $\begin{array}{c}\text { Food Products } \\
\text { Weight Retention } \\
\text { Difficulties for Regular }\end{array}$ \\
\hline Perceived Severity & $\begin{array}{c}\text { Behavioral and Situational } \\
\text { Factors }\end{array}$ & $\begin{array}{c}\text { Resources Stock and } \\
\text { Access }\end{array}$ & Weight Recovery \\
\hline Perceived Costs & Interpersonal Influences & Information & \\
\hline
\end{tabular}

Table 2. Characteristics of mothers (n: 10).

\begin{tabular}{cc}
\hline Characteristic & $\mathrm{N}^{\circ}(\%)$ \\
\hline Age (yr) & \\
$20-29$ & $2(20 \%)$ \\
$30-39$ & $8(80 \%)$ \\
Educational attainment & \\
Secondary school & $1(10 \%)$ \\
Tertiary education & $4(40 \%)$ \\
University degree & $5(50 \%)$ \\
Parity & \\
Primiparous & $4(40 \%)$ \\
Multiparous & $6(60 \%)$ \\
\hline
\end{tabular}

breastfeeding) or due to difficulties encountered with the pregnancy. However, they explained they had difficulties keeping the changes made during the pregnancy after the baby was born, because they forgot about self-care and prioritized behaviors beneficial for the baby or based on their partners' or children's eating preferences, not paying attention to their own diet, consequently disorganizing the eating habits and the family.

Main changes referred included not smoking, and not drinking alcohol since getting pregnant and, in terms of diet, they referred an increase in the consumption of dairy products, fruits, vegetables, water or juices, highlighting the decrease in the consumption of sodas and caffeine. They pointed out the importance of eating four meals, especially breakfast, and the value of food safety.

Women stated they "eat poorly", "do not eat", "eat little", "snack here and there", "eat whatever they find" and they could not even remember what they 
had eaten due to lack of time and family disorganization. They referred feeling ineffective, frustrated and stressed because they cannot put into practice the eating habits they believe are appropriate for breastfeeding, mainly in primiparous women, due to lack of experience.

Regarding commensality, women referred they tried to create shared spaces with their partners, but they found it difficult because they prioritized the demands from the baby, especially during the first month post-partum and among primiparous women. Dinner was the most valuable time to gather the whole family. Having other children helped respect commensality and organize the eating habits. The value given to breastfeeding made these women acquire skills to avoid interrupting it, thus adapting the family table around the baby's schedule.

The perception of the mother's "self-effectiveness" depended on several conditioning factors, such as coping strategies, family conditions, previous knowledge, grocery shopping habits, willpower and professional guidance. Among the strategies used, they referred family help, meal planning, frozen meal preparation, husband in charge of grocery shopping, prepared meals and home delivery (mainly in women having a high socioeconomic status) or shopping at community markets (Table 3 ).

Table 3. Verbatim phrases regarding self-care and value of a healthy diet during breastfeeding.

Perceived Benefits

- “...Eating right or not cannot be the same... It must have something to do with it: if I eat better, my milk should be of a higher quality..."

- "... I believe that it has some influence, in resting, feeding, and other aspects..."

Perceived Costs: Changes in Eating Habits during Breastfeeding

- “... Trying not to skip meals, eating a good breakfast...".

- "I am hungrier now..., I have more appetite now"

- "...In the Hospital, there was a big jug... I used to drink it all (water)... For me, we should follow a varied diet... eating less red meat... vegetables, the more colorful the better, fruits...".

- (Feeding changes because of breastfeeding) "I should (but) I do not... I know I should eat a yogurt for example, since I don't like milk..."

- "Mom helped us a lot. The first week, for example, she invited us to lunch the whole week. Since I was discharged and the first 10 days. I don't always sit down for lunch, that starts to happen..."

- "P $m$ so hungry because somehow I have to produce that milk, because like all the time, but not anxiety, because I $m$ really hungry..."

Perceived Barriers

- “...family (husband and children)... lack of time... In those days where he was so demanding, I did not feel like cooking. So, we resorted to home delivery, easy things..."

- "I should, but I am not taking them (care). I know that, for example, since I do not like milk, I should drink that calcium yoghurt I was told to drink, one per day and then add cheese with a fruit paste as a snack. I do not do it"

- “...My husband works, so he does not cook, I do it, and since I have another daughter and everything else...”

- "...I do not know how to eat right. I tried to stop eating thinks that, based on general knowledge, we assume that they are not good... But I do not have proper knowledge about an ideal diet for breastfeeding. It would be great to have it".

- "... I have less time to eat, I eat poorly..."

- "Sometimes, I find it hard to eat healthy because I don't cook now..." 


\subsection{Connotations Referred to Food Products, Drinks and Supplements}

Women interpreted thirst and hunger as a body need to produce breast milk, to make up for the low weight gain during pregnancy or due to anxiety. Therefore, mothers referred they were eating more food products and drinking more water.

Fruits and vegetables in general have a positive connotation. Cow milk showed opposing views: some of them were drinking more milk while others associated it with negative effects related with their beliefs and ended up avoiding it.

Certain food products considered less healthy were avoided, such as sweets, junk food, sodas, cookies, spices, coffee, mate (to a lesser extent) and alcohol. Reducing the consumption of red meat was found healthy, but they recognized they need to eat it.

Other food products avoided due to potential harmful effects in the baby, the breast milk or the mother included sodas, broccoli, eggplant, tomato, sauces, spices and fish. The women interviewed referred that such food products may impact on milk's taste, quantity or quality ("creamy"; "watery"; "filling"; "they decrease the production") and they may cause discomforts in the baby, such as feeling colicky, sleepy, gassy or constipated.

On the other hand, pasta and rice are replaced by fruits, jellies and juices, based on their association with maternal discomfort ("food poisoning", "heartburn", "they are heavy to digest", constipation and post-partum hemorrhoids if they had a C-section).

In general, mothers stated they usually stop eating a specific food product if they relate its consumption to the appearance of some discomfort in them, followed by discomfort in their baby.

They also talked about the consumption of food products having personally valued positive properties such as coconut oil, fish, seeds, almonds and raisins.

When a woman is breastfeeding, supplements are less often prescribed. Faced with this situation, women took two different stands: a group stated they did not use them if supplements had not been prescribed to them, and even rejected them because they considered they were "not natural". On the other hand, the other group stated they personally wanted to use them to combat tiredness. They referred a disparate consumption of supplements (iron, folic acid, calcium, vitamins) during pregnancy (Table 4).

\subsection{Body Image and Post-Partum Weight Retention}

There is lack of knowledge on what should be an appropriate weight gain during pregnancy. It is worth noting that mothers consider an 8 or 9-kilogram gain as a target accomplished, affected by their own aesthetical considerations and a positive assessment of their pairs. Overweight and absent tone are stated as the reasons for being unhappy with their own image, especially in primiparous women or those who performed sport activities before they got pregnant. Despite this, 
Table 4. Verbatim phrases about connotations referred to food products, drinks and supplements.

Connotations referred to Food Products

- "...I try to eat every day... something having calcium... I do it because I understand that breastfeeding produces decalcification and I do not want to lose any teeth..."

- “...I was told... that drinking milk while breastfeeding was a contradiction... I somewhat respect that..."

- "... I do not like... meat... iron is important... I should cut out on the number of cookies I eat..."

- "...I try to eat a cheese portion every day or something similar containing calcium... I had already included them a little bit during pregnancy..."

- "Since I suspected I was pregnant, I did not take one more drop of alcohol, although I love it"

- "I can't drink alcohol, or for example, I love coffee and I know I have to drink less now..."

Perceived Severity: Food Products affecting the Milk or the Baby

- “... My baby was gassy so I was recommended not to drink sodas, eat spicy food..."

- "...If you notice that something ( a food product) upsets your stomach, that something upsets her stomach and you have just eaten a certain food product, well..."

- "I think the only thing I don't eat is broccoli (because)... milk changes the taste with it"

Supplements and Breastfeeding

- "...Mostly iron... but actually... taking medicines is not my thing..."

- “...I asked my obstetrician to prescribe vitamins for me as soon as the baby was born..."

they were waiting to complete the exclusive breastfeeding period to start focusing on coming back to their standard weight.

The association between breastfeeding and previous weight recovery was weak and doubted. The mothers who lost weight were the only ones who thought it was due to breastfeeding (Table 5). The factors identified as influencing in the weight decrease were, in the first place, physical activity, then, taking care of their eating habits and, lastly, breastfeeding.

\subsection{Information Sources Consulted}

The women interviewed stated they had not received or found information about eating and breastfeeding, acknowledging there is "lack of information" on the subject. Main references for consultation when having doubts or needing healthy guidelines were obstetricians during pregnancy and pediatricians during breastfeeding.

The nutritionist comes up as a possible reference, but none of the interviewed women actually scheduled a visit with one during pregnancy or breastfeeding. A limiting factor mentioned was "having to visit another professional, besides the ones already implied in pregnancy".

The nursing consultants ("puericultoras"), especially since they offered home services, were valued because they provided emotional support, assistance and encouragement for a successful breastfeeding.

Doubts, crisis situations caused by the baby's crying or pain, milk "coming in" or lack of professional advice made women resort to family members (in general, the baby's grandmother) or friends as information sources. Since they had strong affective ties to those sources, professional advice usually ended up invalidated.

Some mothers stated they needed more information during pregnancy than 
Table 5. Verbatim phrases about body image and post-partum weight retention: beliefs (knowledge) and attitudes.

- “...A little bit of willpower. Exercising, eating properly. It is said that the weight you gained can be lost breastfeeding but... I do not realize whether I lost weight because of that..."

- "...It is said, and I believe it, that breastfeeding affects your weight but, in my case, I believe it is the high-paced rhythm..."

- “... Of course, I knew that breastfeeding helped losing weight, not lose weight... but lose calories, I imagine. I believe it has to do with calories"

during breastfeeding, because the latter is perceived as a "natural" time in which there is no need to learn from others (Table 6).

\section{Discussion}

This study was aimed at identifying and describing conceptual models from women during the breastfeeding period in relation with the importance given to eating as a self-care measure; connotations referred to food products, drinks and supplements, post-partum weight retention and information sources consulted. Findings show that maternal eating comes up as a health conditioning factor since pregnancy.

During breastfeeding, there were conditioning barriers found for having healthy eating habits, mainly family disorganization, making food choice and commensality difficult. Breastfeeding was not directly associated with weight loss. Mothers were seen unsatisfactory with their own body, showing certain disregard for it during the first months, since the focus was placed on the baby. The information sources referred were diverse and, when faced with contradicting messages, the sources chosen were the ones with strong affective ties.

As seen in previous researches, mothers acknowledged the need to follow a special diet during the breastfeeding period. As a rule, healthy food products that should be included and foods considered prohibited were listed. A Brazilian study on social representations in breastfeeding mothers showed that "healthy" and/or "strong" food products were associated with a high content of iron and vitamins (fruits, vegetables, meats, rice and liquids) to avoid maternal weight loss, "to enrich" breast milk and benefit the baby. "Prohibited" or unhealthy food products included chocolate, ground pepper, some vegetables (cabbage, pepper), alcohol, coffee and cow milk [12]. As shown by the findings of this study, food products considered unhealthy were often cut out to protect milk production, avoid digestive discomfort or possible baby allergies, among other reason [12] [13] [14]. Vallianatos et al. [15] showed the need to "eat for two" as a cultural belief to assure there is enough milk production and well-being for the mother and the nursing baby. These ingrown beliefs, mostly having not enough scientific grounds, could lead to breastfeeding mothers having unbalanced eating practices [16]. Raman et al. highlight there is a high diversity observed when valuing food products and their restriction or consumption in a review on cultural practices and beliefs in perinatal nutrition, in low and middle-income countries. 
Table 6. Verbatim phrases about the commonly consulted information sources, skills and interpersonal influences.

- “...There is not much information... I have asked the pediatrician... I do not get any answers... Not about nutrition..."

- "And now, to the pediatrician. But I was not really convinced, and I also have friends who told me... My friend s baby was gassy, so she was recommended not to drink sodas, not to eat spicy food. Those things are anyway known or said..."

- "...A nursing consultant... she came here one day. We were there: my husband, her (the baby), the nursing consultant and myself... It was great..."

- I don't have that information and people talk about protein, diet and I don't know how to distinguish... I don't know how to eat well. I tried to remove things that by general knowledge I assume do not do well.

- "I don't have a good knowledge of an ideal diet for breastfeeding. It would be great"

Food products valued as good or bad did not have major consensus among countries or even among close populations. The revision reaches the conclusion that dietary restrictions based on cultural reasons are ingrown and widely spread around Asia, Africa and some areas in Latin America [17].

As shown by the findings of this study, publications made in different contexts highlighted that the knowledge about puerperal self-care is scarce, pointing out that the Health Team does not provide education on the subject and that the main information source in primary care was the midwife or cultural beliefs [16] [17] [18].

The results of this study regarding the concern on body weight are aligned with a previous study conducted in Sweden, where mothers stated they did not know what the recommended weight gain during pregnancy was or the risks it could cause for the delivery and the weight retention afterwards [19]. Although there is a physiological mechanism that uses women's fat reserves for milk synthesis, mothers did not consider breastfeeding to have a positive effect in post-partum weight loss. Evidence available in this field shows inconsistencies, although minor positive effects of breastfeeding in weight loss are observed [20] [21] [22]. This study did not show the practice of eating to obtain "well-being" or relief from the tiredness and pain, since appetite increase was interpreted as a biological effect of milk production [19]. Regarding body image dissatisfaction, a Chilean study also showed that most mothers (76\%) referred negative changes in the body shape and breasts [23].

The use of supplements was scarce and only based on the mother's wish, in alignment with a Spanish study, which showed that only $22 \%$ of breastfeeding mothers use them [24].

"Self-effectiveness" and the "value of a target" came up evidently in the use of coping strategies to deal with the barriers shown (stress, tiredness, disorganization and family needs). The higher the value the mother placed on breastfeeding for the baby's health, the greater her motivation to continue breastfeeding. According to Cerda Muñoz L. [25], the breastfeeding mother has a better development of self-esteem and self-confidence, since she can prove the ability only mothers have of feeding their children, satisfying their needs and creating the 
bonding. Several studies show that the intra- or extra-family social network provides the support needed for the mother to continue breastfeeding and for her own self-care [19] [25]. On the other hand, to achieve better coping strategies, mothers demanded more attention from the health team, usually absent, since they focus exclusively on the newborn [16] [19].

\section{Conclusions}

A woman's behavior, in terms of taking care of her own eating habits during the breastfeeding period is influenced by culture and social context, including beliefs, feelings, perceptions, values, motivation and attitudes, among other factors. This study identified and characterized beliefs and barriers for maternal eating with the aim of including the socio-cultural aspect both in the design of public health policies and in the contextualized individual dietary-nutritional approach. If tensions between social beliefs and messages from health professionals could be reduced, a higher compliance of recommendations could be attained.

The post-partum period, which can be considered an inter-gestational time, is an opportunity to provide health interventions, allowing the mother to feel emotionally supported so that she can continue with the changes made in her eating habits, if done so during pregnancy. Providing support when breastfeeding and the dietary-nutritional follow-up needed to make weight recovery easier and prevent overweight would allow her to face a new pregnancy having a higher level of knowledge, self-confidence and a better nutritional status. The perception of an increase in family complexity focusing on the newborn makes it relevant and needed to start educating since the pregnancy about self-care during the post-partum period. In the long run, perinatal interventions should be aimed at improving maternal nutrition and weight through a multidisciplinary approach, so as to reduce the potential of transgenerational transmission of obesity risks and other non-transmissible chronic diseases.

Finally, and based on the lack of local data, we recommend that quantitative studies are conducted to describe the characteristics of maternal eating during the breastfeeding period, focusing on the intake of critical nutrients and how the analyzed factors affect the actual eating habits during this period.

\section{Conflicts of Interest}

The study was funded by Danone Nutricia Early Life Nutrition. Prof. Lic Gabriela Olagnero is Scientific Coordinator in Research and Development, Danone Nutricia Early Life Nutrition.

\section{References}

[1] Vitora, C. (2012) Los mil días de oportunidad para intervenciones nutricionales. De la concepción a los dos años de vida. Archivos Argentinos de Pediatría, 110, 311-317. https://doi.org/10.5546/aap.2012.311

[2] Institute of Medicine, National Academy of Sciences. (US) Committee on Nutritional Status during Pregnancy and Lactation (1991) Nutrition during Lactation. 
National Academies Press (US), Washington DC.

[3] Latham, M.C. (2002) Nutrición humana en el Mundo en Desarrollo. Food and Agriculture Organization, Roma.

[4] Ministerio de Salud de la Nación, Dirección Nacional de Maternidad e Infancia (2017) Situación de la lactancia materna en Argentina. Año 2015.

http://datos.dinami.gov.ar/produccion/nutricion/material/Encuesta-Nacional-de-La ctancia-Materna-2015.pdf

[5] Coordinación IBFAN Argentina (2017) Iniciativa Mundial sobre Tendencias de la Lactancia Materna (WBTi) Primer Informe, Argentina, 2009.

http://www.worldbreastfeedingtrends.org/GenerateReports/report/WBTi-Argentina -2008.pdf

[6] Zapata, M.E., Rovirosa, A., Pueyrredón, P., Weill, F., Chamorro, V. and Carella, B. y col. (2016) Situación alimentaria nutricional de las embarazadas y madres en periodo de lactancia de Argentina. DIAETA. Buenos Aires, 34, 33-40.

[7] Moreno San Pedro, E. and Roales-Nieto, J.G. (2003) El modelo de Creencias de Salud: Revisión Teórica, consideración crítica y propuesta alternativa. Revista internacional de Psicología y Terapia Psicológica, 3, 91-109.

[8] Rios Hernández, I. (2011) Comunicación en Salud. Conceptos y Modelos teóricos. Perspectivas de la comunicación, 4, 123-140.

[9] Pender, N.J. (2011) Health Promotion Model Manual, University of Michigan, 2011. http://hdl.handle.net/2027.42/85350

[10] Strauss, A. and Corbin, J. (2002) Bases de la Investigación Cualitativa. Técnicas y procedimientos para desarrollar la Teoría Fundamentada. Primera edición (en español) Editorial Universidad de Antioquia, Publicado por acuerdo con Sage Publications, Inc. Universidad de Antioquia, Colombia.

[11] Hernández Sampieri, R., Fernández-Collado, C. and Baptista Lucio, P. (2006) Metodología de la investigación. 4a edición, McGraw-Hill Interamericana Editores, México.

[12] Souza, M.E., Mitre, C.R.M., Vieira, B.M.I., Castro, F.S. do C. and Amaral, A.R.M. (2011) Representações sociais sobre a alimentação da nutriz. Ciência \& Saúde Coletiva [Internet], 16, 4267-4274.

http://www.scielo.br/scielo.php?script=sci_arttext\&pid=S1413-81232011001100032 \&lng=en. http://dx.doi.org/10.1590/S1413-81232011001100032 https://doi.org/10.1590/S1413-81232011001100032

[13] Jeong, G., Park, S.W., Lee, Y.K., Ko, S.Y. and Shin, S.M. (2017) Maternal Food Restrictions during Breastfeeding. Korean Journal of Pediatrics, 60, 70-76. https://doi.org/10.3345/kjp.2017.60.3.70

[14] Ahlqvist, R.N. and Wirfält, E. (2000) Beliefs Concernings Dietary Practices during Pregnancy and Lactation. Scandinavian Journal of Caring Sciences, 14, 105-111. https://doi.org/10.1111/j.1471-6712.2000.tb00570.x

[15] Vallianatos, H., Brennand, E.A., Raine, K., Stephen, Q., Petawabano, B., Dannenbaum, D., et al. (2006) Beliefs and Practices of First Nation Women about Weight Gain during Pregnancy and Lactation: Implications for Women's Health. CJNR, 38, 102-119.

[16] Chimbo Oyaque, C.E. (2014) Prácticas y conocimientos, creencias y tabús alimentarios que influyen en el estado nutricional de las mujeres gestantes y lactantes atendidas en el Centro de Salud de Huachi Chico durante el período junio-noviembre del 2013. Universidad técnica de Ambato, Facultad de Ciencias de la Salud, Carrera de Medicina, Informe de Investigación, Ambato. 
[17] Raman, S., Nicholls, R., Ritchie, J., Razee, H. and Shafiee, S. (2016) Eating Soup with Nails of Pig: Thematic Synthesis of the Qualitative Literature on Cultural Practices and Beliefs Influencing Perinatal Nutrition in Low and Middle Income Countries. BMC Pregnancy Childbirth, 16, 192. https://doi.org/10.1186/s12884-016-0991-z

[18] Gómez-Ortiz, M.C., Labandeira-López, P., Núñez-Vivas, M., Mengíbar-Carrillo, A., Vallecillos-Zuya, S. and Hernández-Martínez, A. (2014) Necesidades educativas sobre autocuidados y factores relacionados en el puerperio domiciliario. Matronas Profesión, 15, 10-17.

[19] Christenson, A., Johansson, E., Reynisdottir, S., Torgerson, J. and Hemmingsson, E. (2016) Women's Perceived Reasons for Their Excessive Postpartum Weight Retention: A Qualitative Interview Study. PLoS ONE, 11, e0167731. https://doi.org/10.1371/journal.pone.0167731

[20] Neville, C.E., McKinley, M.C., Holmes, V.A., Spence, D. and Woodside, J.V. (2014) The Relationship between Breastfeeding and Postpartum Weight Change DA Systematic Review and Critical Evaluation. International Journal of Obesity, 38, 577-590.

[21] Lopez-Olmedo, N., Hernandez-Cordero, S., Neufeld, L.M., Garcia-Guerra, A., Mejia-Rodriguez, F. and Gomez-Humaran, I.M. (2016) The Associations of Maternal Weight Change with Breastfeeding, Diet and Physical Activity during the Postpartum Period. Maternal and Child Health Journal, 20, 270-280.

[22] Antonakou, A., Papoutsis, D., Panou, I., Chiou, A. and Matalas, A.L. (2013) Role of Exclusive Breastfeeding in Energy Balance and Weight Loss during the First Six Months Postpartum. Clinical and Experimental Obstetrics and Gynecology, 40, 485-488.

[23] De los Reyes Muñóz, M.O. and Drewes Araneda, X.C. (1991) Problemas más frecuentes en la mujer primípara que amamanta y su recién nacido al momento del alta de la maternidad. Pontificia Universidad Católica de Chile, Escuela de Enfermería, Santiago, $108 \mathrm{p}$.

[24] Cuervo, M., Sayon-Orea, C., Santiago, S. and Martínez, J.A. (2014) Dietary and Health Profiles of Spanish Women in Preconception, Pregnancy and Lactation. $\mathrm{Nu}$ trients, 6, 4434-4451. https://doi.org/10.3390/nu6104434

[25] Cerda Muñoz, L. (2011) Lactancia materna y gestión del cuidado. Revista Cubana de Enfermería, 27, 327-336. 